\title{
A Novel Evaluation Approach for Tourist Choice of Destination Based on Grey Relation Analysis
}

\author{
Xudong Guo ${ }^{1,2}$ and Zilai Sun ${ }^{2}$ \\ ${ }^{1}$ Tourism and Historical Culture College, Zhaoqing University, Yingbin Avenue, Zhaoqing 526061, China \\ ${ }^{2}$ Institute of Systems Engineering, Dalian University of Technology, No. 2, Linggong Road, Ganjingzi District, Dalian 116024, China \\ Correspondence should be addressed to Zilai Sun; sunzilai@mail.dlut.edu.cn
}

Received 16 June 2016; Revised 16 August 2016; Accepted 21 August 2016

Academic Editor: Guo Chen

Copyright (c) 2016 X. Guo and Z. Sun. This is an open access article distributed under the Creative Commons Attribution License, which permits unrestricted use, distribution, and reproduction in any medium, provided the original work is properly cited.

\begin{abstract}
The decision-making process of choosing an ideal tourism destination is influenced by a number of psychological and nonpsychological variables. Tourists need a method to quickly and easily select a suitable destination. Driven by this practical decision issue, a novel approach of tourist destination evaluation, grey relation analysis (GRA), is developed and applied to the ranking evaluation of Taiwan tourism destinations in China. In the evaluating process, we apply entropy to calculate the weight of each index, which is a more objective method of calculating weights. The results of the study indicate that although the same size is small and the distribution of data is unknown, GRA can still be successfully used in evaluating tourist destinations. In addition, we compare the GRA results with the Technique for Order Preference by Similarity to Ideal Solution (TOPSIS) and show that more accurate ranking results can be obtained.
\end{abstract}

\section{Introduction}

With the development of social economy and the improvement of people's living standard, more public holidays, faster transportation (e.g., convenient air networks and highspeed railways), and greater openness toward the world, China's domestic and outbound demand for tourism have grown unprecedentedly since the 2000s [1]. According to the National Bureau of Statistics of China, the number of domestic tourists reached 3,611 million in 2014. In addition, the number of overseas visitor arrivals was 128.4983 million and the number of Chinese outbound visitors was 107.2755 million in 2014. Along with the significant growth in tourism, tourism expenditure and foreign exchange earnings in China have also increased significantly. In 2014, China's earnings from domestic tourism reached RMB 3,031.18 billion, and the foreign exchange earnings from international tourism reached USD 56,913 million. In tandem with the tremendous development of China's tourism economy, China's government has committed to making tourism development a major policy, while China already has so much to offer to international and domestic travelers: its natural beauty; a rich culture; great cuisine; amazing technological advancement; and friendly citizens. According to the China National Tourism Administration, by 2014, China has 184 5A-class tourist scenic spots, 8625 -star hotels, and 600 travel agencies [2], as shown in Figure 1. Tourism has become one of the strongest and largest industries and turned into the period of buyer's market in China's process of development.

One of the biggest issues facing the tourist today is how to evaluate and rank the tourism destination, as well as the need to understand what factors influence their choices [3]. However, the decision-making process of choosing an appropriate travel destination is a very complex process, and choosing a viable method for effective evaluation of tourism destination is not an easy task. There is a substantial body of literature discussing different research methods applied to evaluation and choice of tourism destination. These methods include (1) Multinomial Logit Model (MNL) [4-7]; (2) Binary Regression Model [8-11]; (3) Multinomial Probit Model [12]; (4) Scobit Based Discrete-Continuous Choice Model [13]; (5) Structural Equation Model [14-19]; (6) Meta-analysis 


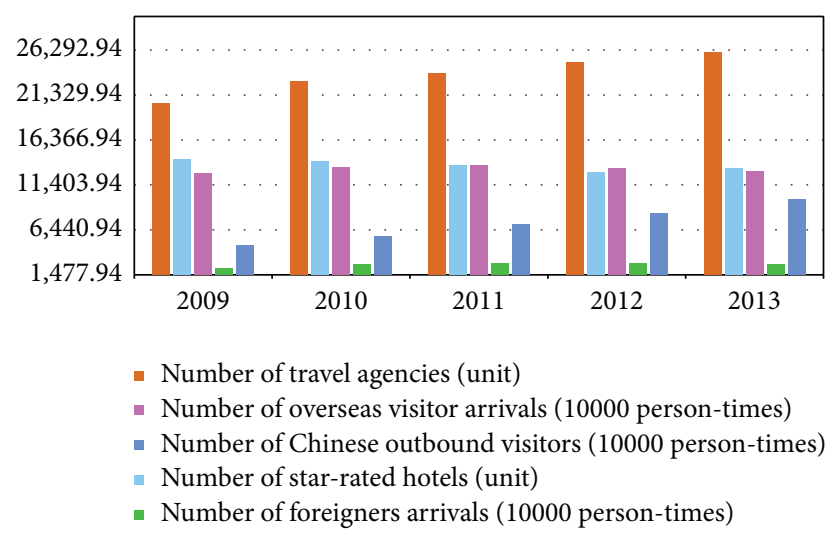

Figure 1: China's tourism development situation for nearly five years.

[20]; (7) Technique for Order Preference by Similarity to Ideal Solution (TOPSIS) [21-24]; (8) Principal Component Analysis [25-30]; and (9) Analytic Hierarchy Process (AHP) [31-37]. Some of the methods may have already been known to the public. Other methods were simply borrowed from the domain of industrial study and applied to tourism. Some are still in the embryonic stage. Each of the above nine methods can be independently applied to evaluate tourism destination. However, none of them is perfect. Researchers can only choose a method to evaluate tourism destination that has the least amount of drawbacks for that study's particular situation. Some evaluation methods require the high quality data; that is, the data should obey a certain distribution or the data volume should be large. In addition, the other evaluation methods have strong subjectivity.

Therefore, a viable method for effective evaluation of tourism destination is aimed at providing solutions for issues with multiple variables and targets. However, in studying the evaluation of tourism destination, survey data are often incomplete or unclear, and this paper therefore is bound by realistic limits, confining itself to a situation where the amount of data is small and its significance indefinite. Given these considerations, grey relation analysis (GRA) may be the best method for this study and will be used to explore practical procedure of tourist destination evaluation and choice to identify the various features that need to reflect preferences of tourists for destinations in the context of 8 tourist spots by utilizing the index system and data in literature [21]. On the basis of such preliminary analysis, this paper intends to achieve twofold aims. The first applies entropy to find the relative weights of each index of the 8 tourist spots. The second is to rank the tourist spots by grey relation analysis (GRA) and compare the ranking results with literature [21].

The rest of this paper is organized as follows. After a brief review of relevant literature in Section 2, we present hierarchy of tourism destination selection and evaluation index system in Section 3. The grey relation analysis evaluation model for tourism destinations selection is presented in Section 4.
Section 5 illustrates the results obtained from the grey relation analysis evaluation model and then, we compare and analyze these results with those obtained from the Technique for Order Preference by Similarity to Ideal Solution (TOPSIS) evaluation method used by literature [21]. Conclusions are drawn in Section 6.

\section{Literature Review}

Evaluation and choice of tourism destination is one of the important topics frequently investigated by scholars [38]. These evaluation and choice studies have been linked to the issues of decision rules, decision-making processes, and choice factors [5, 39-45]. Hsu et al. [21] proposed a 4-level AHP model, consisting of 22 attributes on the 4 th level and tested it using data collected from tourists visiting Taiwan to establish the relative importance of preselected factors (criteria). In this study, visiting friends/relatives and personal safety appear to be the 2 most important factors for inbound tourists to Taiwan, price is the least important, and Taipei 101 is the first priority for travelers. Huybers [46] applied discrete choice modeling technique to study the short-break destination choices of prospective Sydney residents. The study results show that a destination's attractiveness to prospective shortbreak visitors from Sydney is enhanced, to different degrees, by lower prices, being moderately busy, having a moderate level of night life, being visited during spring/summer, being accessible within two hours' travel time, and offering a mix of natural and cultural/heritage attractions. Prayag and Ryan [14] used confirmatory factor analysis to explore the relationships among four constructs, namely, destination image, place attachment, personal involvement, and visitors' satisfaction as antecedents of loyalty. The research findings indicate that destination image, personal involvement, and place attachment are antecedents of visitors' loyalty but this relationship is mediated by satisfaction levels.

Dellaert et al. [47] pointed out that tourists' choices are complex multifaceted decisions where the choices for different elements are interrelated and evolved in a decision process over time. The decision-making process is influenced by a number of psychological (internal) and nonpsychological (external) variables. Sirakaya and Woodside [48] provided a comprehensive qualitative review of the tourist decision-making literature and integrated the main conceptual and empirical work that has been reported in the tourism literature. Lam and Hsu [49] argued that the complex decision-making process leading to the choice of a travel destination had not been well researched. Past studies related to destination choice mainly focus on identifying important attributes affecting destination choice; professional judgment and factor analysis are the main methods [50-53]. Richards and Wilson [54] in their work focused on independent youth and student travel and used factor analysis to help identify four main motivating factors, including experience seeking, relaxation seeking, and sociability and contributing to the destination. Tomiš et al. [55] studied the factors considered 


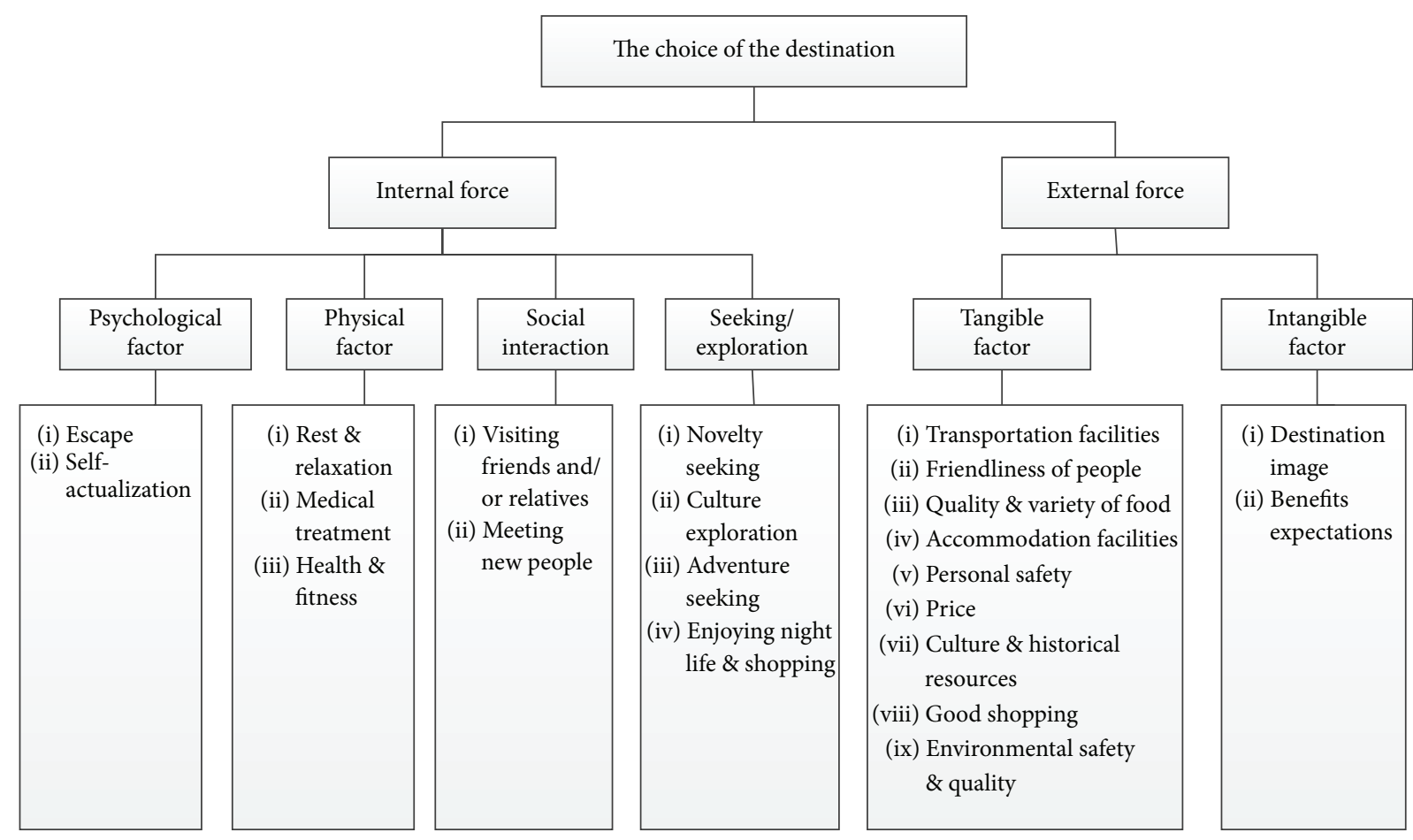

FIgURE 2: The hierarchy of destination selection (source: Hsu et al. [21]).

by young people when choosing a city destination in Europe and identified seven major factors: partying and having fun, accessibility to destination info, easy and cheap travel organization, outdoor activities, socializing with the local people, good shopping places, and exploring the unknown. Further analysis showed that there are significant differences among several motivation factors when it comes to Danish and international students. Pike and Page [30] provided a comprehensive narrative analysis of the destination marketing literature.

The above studies mainly applied qualitative and quantitative methods to analyze the factors influencing the choice of tourism destinations. They pointed out that the decisionmaking process leading to the final choice of a travel destination is very complex. However, these studies failed to consider the preferences of tourists in the decision-making process and utilize much more complex decision-making approaches. Motivated by this, we develop a new evaluation model to evaluate and rank the tourism destinations considering personal preferences. Thus, we attempt to evaluate the preferences of tourists for destinations and recognize the key aspects influencing the tourists' choice of destination. Finally, Guo et al. [56] proposed a novel similarity-based algorithm for classifying tourism scenic spots, and this evaluation method not only has some similarities to our own but also has some key differences. They studied the problem of classifying different tourism scenic spots into different levels through calculating the relative similarity of each scenic spot to the best and worst scenic spots, but, in our model, we do not consider the worst scenic spots, which make the evaluation process simple and easy to conduct.

\section{The Hierarchy of Tourism Destinations Selection}

According to $\mathrm{Hsu}$ et al. [21], the main factors affecting tourism destination choice are grouped into two categories, namely, internal and external factors. The push motivation relates to internal forces which consist of 4 criteria (psychological, physical, social interaction, and seeking/exploration) and are further divided into 11 subcriteria. The pull motivation relates to external forces which consist of 2 criteria (tangible and intangible) with tangible criteria including 9 subcriteria and intangible criteria including 2 subcriteria (see Figure 2).

\section{The Grey Relation Analysis Model of Tourism Destination Choice}

Grey relation analysis (GRA) is a method that can be used in decision-making in situations where there are many criteria by ordering them as to relational grade. It is especially preferred in ordering the alternatives in situations in which the sample is small and sample distribution is not known. GRA is part of the grey system theory [57]. Gray system theory was first introduced by Ju-Long [58]. The fundamental definition of "greyness" is information being incomplete or unknown; 
thus an element from an incomplete message is considered to be of "grey" element. A "grey relation" refers to the measurement of changing relations between two systems or elements that occur in a system over time. The analysis method, which measures the relations between elements based on the degree of similarity or difference of development trends among these elements, is called "grey relation analysis." More precisely, during the process of system development, should the trend of change between two elements be consistent, it then enjoys a higher grade of synchronized change and can be considered as having a greater grade of relation; otherwise, the grade of relation is smaller [59]. It has been widely applied in a variety of fields such as financial performance evaluation [60$64]$, motor vehicular energy consumption $[65,66]$, and green supplier selection [67]. As far as we know, GRA has not been applied in evaluation and choice of tourism destination. We believe we are the first to utilize the GRA to evaluate and rank the tourism destinations.

Personal preferences, like motivations, may be both intrinsic, reflecting individual likes and dislikes, and extrinsic, or socially conditioned. Pearce [68] stated that preferences are more specific than motivations and are revealed by where travelers go and what travelers do. However, tourists' preferences are psychological behaviors, which are not easy to accurately measure, having the feature of grey and fuzzy. Choosing a tourism destination is a grey system evaluation process; therefore, the grey relation analysis is a more suitable method to evaluate it. The evaluation procedure of this study consists of several steps. The detailed descriptions of each step are given in the following subsections.

4.1. Problem Definition. Assume that there are $n$ tourism destinations $\left\{T_{1}, T_{2}, \ldots, T_{n}\right\}$, which are to be evaluated in terms of $m$ evaluation criteria $\left\{C_{1}, C_{2}, \ldots, C_{m}\right\}$, and relative weights are denoted by $\omega_{i j}\left(\sum_{j=1}^{m} \omega_{i j}=1\right)$. The objective of the decision-making is to rank these tourism destinations. According to the assumption, we can get the original index data matrix

$$
R=\left(r_{i j}\right)_{n \times m}=\left[\begin{array}{cccc}
r_{11} & r_{12} & \cdots & r_{1 m} \\
r_{21} & r_{22} & \cdots & r_{2 m} \\
\vdots & \vdots & & \vdots \\
r_{n 1} & r_{n 2} & \cdots & r_{n m}
\end{array}\right] \text {, }
$$

where $r_{i j}$ is the observed value of object $T_{i}$ in terms of criteria $C_{j}(i=1,2, \ldots, n ; j=1,2, \ldots, m)$.

Definition 1. The best tourism destination is the referential sequence made up of the best tourism destination indexes among all the alternative tourism destinations; that is,

$$
R_{0}=\left(r_{01}, r_{02}, \ldots, r_{0 j}\right)
$$

where $r_{0 j}=\operatorname{Optimum}\left(r_{i j}\right)(i=1,2, \ldots, n ; j=1,2, \ldots, m)$.
So, we can construct initial matrix $R_{1}$ :

$$
R_{1}=\left(r_{i j}\right)_{n \times m}=\left[\begin{array}{cccc}
r_{01} & r_{02} & \cdots & r_{0 m} \\
r_{11} & r_{12} & \cdots & r_{1 m} \\
r_{21} & r_{22} & \cdots & r_{2 m} \\
\vdots & \vdots & \cdots & \vdots \\
r_{n 1} & r_{n 2} & \cdots & r_{n m}
\end{array}\right] .
$$

4.2. Normalization of Index Values. In order to make comparison between the various indicators, we normalized each of the index values in accordance with the following formulas. For larger-is-better transformation, $r_{i j}$ can be transformed to $x_{i j}$. The formula is defined as

$$
X_{i j}=\frac{r_{i j}-\min _{j} r_{i j}}{\max _{j} r_{i j}-\min _{j} r_{i j}} .
$$

For smaller-is-better transformation, the formula to transform $r_{i j}$ to $x_{i j}$ is

$$
X_{i j}=\frac{\max _{j} r_{i j}-r_{i j}}{\max _{j} r_{i j}-\min _{j} r_{i j}} .
$$

The normalized values form a new matrix as shown in

$$
X=\left(x_{i j}\right)_{n \times m}=\left[\begin{array}{cccc}
x_{01} & x_{02} & \cdots & x_{0 m} \\
x_{11} & x_{12} & \cdots & x_{1 m} \\
x_{21} & x_{22} & \cdots & x_{2 m} \\
\vdots & \vdots & \cdots & \vdots \\
x_{n 1} & x_{n 2} & \cdots & x_{n m}
\end{array}\right] \text {. }
$$

4.3. Calculating Grey Relation Coefficient. According to JuLong [69], let $X_{0}=\left(x_{01}, x_{02}, \ldots, x_{0 m}\right)$ as referential sequence and $X_{i}=\left(x_{i 1}, x_{i 2}, \ldots, x_{i m}\right)$ as comparative sequence. Then $x_{0 j}$ and $x_{i j}$ would be the values of $x_{0}$ and $x_{i}$ at optimum index $j$. If $\xi\left(x_{0 j}, x_{i j}\right)$ are real numbers, then they can be defined as

$$
\xi\left(x_{0}, x_{i}\right)=\frac{1}{m} \sum_{j=1}^{m} \xi\left(x_{0 j}, x_{i j}\right) .
$$

The mean of $\xi\left(x_{0 j}, x_{i j}\right)$ needs to meet the four axioms of grey relation.

Axiom 1 (norm interval). Consider

$$
\begin{aligned}
& 0<\xi\left(x_{0 j}, x_{i j}\right) \leq 1 . \\
& \xi\left(x_{0 j}, x_{i j}\right)=1 \leftrightarrow x_{0 j}=x_{i j} \text { (this is called complete } \\
& \text { relation). }
\end{aligned}
$$

$\xi\left(x_{0 j}, x_{i j}\right)=0 \leftrightarrow x_{0} \in \varphi, x_{i} \in \varphi$ (this is called complete nonrelation), where $\varphi$ is an empty set.

Axiom 2 (duality symmetric). Consider

$$
\begin{aligned}
& x_{0}, x_{i} \in X . \\
& \xi\left(x_{0 j}, x_{i j}\right)=\xi\left(x_{i j}, x_{0 j}\right) \leftrightarrow X=\left(x_{0}, x_{i}\right) .
\end{aligned}
$$


Axiom 3 (wholeness). Consider

$x_{j}, x_{i} \in X$

$\xi\left(x_{0 j}, x_{i j}\right) \neq \xi\left(x_{i j}, x_{0 j}\right)$; this case almost always happened.

Axiom 4 (approachability). Consider

$\xi\left(x_{0 j}, x_{i j}\right)$ get larger along with $\left|x_{0 j}-x_{i j}\right|$ getting smaller.

If the abovementioned four axioms could all be satisfied, $\xi\left(x_{0}, x_{i}\right)$ is designed as the grade of grey relation in $x_{i}$ correspondence to $x_{0}$, and $\xi\left(x_{0 j}, x_{i j}\right)$ is said to be the grey relational coefficient of $x_{i j}$ to $x_{0 j}$ at optimum index $j$. Professor Ju-Long [58] proposes a mathematical equation that will satisfy these four axioms of grey relation, which is as follows:

$$
\begin{aligned}
\xi\left(X_{0 j}, X_{i j}\right) & \\
= & \frac{\min _{i} \min _{j}\left|X_{0 j}-X_{i j}\right|+\rho \max _{i} \max _{j}\left|X_{0 j}-X_{i j}\right|}{\left|X_{0 j}-X_{i j}\right|+\rho \max _{i} \max _{j}\left|X_{0 j}-X_{i j}\right|},
\end{aligned}
$$

where $\rho \in[0,1]$ is distinguished coefficient, the function of which is to reduce its numerical value by $\max _{i} \max _{j}\left|X_{0 j}-X_{i j}\right|$ increasing, so as to affect its loss-authenticity and to heighten the significance of difference among relational coefficients, and $\rho=0.5$ is generally used. Relational coefficients $\xi\left(X_{0 j}, X_{i j}\right)$ matrix can be obtained through formula (8). As a matter of convenience, we use $\xi_{i j}$ instead of $\xi\left(X_{0 j}, X_{i j}\right)$ in the following pages:

$$
E=\left(\xi_{i j}\right)_{n m}=\left[\begin{array}{cccc}
\xi_{11} & \xi_{12} & \cdots & \xi_{1 m} \\
\xi_{21} & \xi_{22} & \cdots & \xi_{2 m} \\
\vdots & \vdots & & \vdots \\
\xi_{n 1} & \xi_{n 2} & \cdots & \xi_{n m}
\end{array}\right]
$$

4.4. Determining the Index Weights Based on Entropy. Making normalization processing for formula (9), $\xi_{i j}$ can be transformed to $\mu_{i j}$, and a new matrix (9) can be obtained as follows:

$$
\begin{aligned}
E_{0}=\left(\mu_{i j}\right)_{n m}=\left[\begin{array}{cccc}
\mu_{11} & \mu_{12} & \cdots & \mu_{1 m} \\
\mu_{21} & \mu_{22} & \cdots & \mu_{2 m} \\
\vdots & \vdots & & \vdots \\
\mu_{n 1} & \mu_{n 2} & \cdots & \mu_{n m}
\end{array}\right] \\
(i=1,2, \ldots, n ; j=1,2, \ldots, m),
\end{aligned}
$$

where $0 \leq \mu_{i j} \leq 1$ and $\sum_{i=1}^{n} \mu_{i j}=1$; then, the information entropy is

$$
H(j)=-\sum_{i=1}^{n} \mu_{i j} \cdot \log \mu_{i j}
$$

Let

$$
v_{i j}=1+\frac{\sum_{i=1}^{n} \mu_{i j} \cdot \log \mu_{i j}}{\log n} .
$$

Then, we obtain the weights of indexes in terms of formula (12):

$$
\omega_{i j}=\frac{v_{i j}}{\sum_{j=1}^{m} \nu_{i j}}\left(0 \leq \omega_{i j} \leq 1, \sum_{j=1}^{m} \omega_{i j}=1\right) .
$$

4.5. Calculating Grey Relational Grade. After obtaining the grey relational coefficient, we normally take the weighted value of the grey relational coefficient multiplied by weighting value as the grey relational grade. The grey relational grade is defined as follows [70]:

$$
\begin{aligned}
B & =\omega_{i} \cdot\left(\xi_{i j}\right)_{n m}^{T}=\omega_{i} \cdot\left[\begin{array}{cccc}
\xi_{11} & \xi_{21} & \cdots & \xi_{n 1} \\
\xi_{12} & \xi_{22} & \cdots & \xi_{n 2} \\
\vdots & \vdots & & \vdots \\
\xi_{1 m} & \xi_{n 2} & \cdots & \xi_{n m}
\end{array}\right] \\
& =\left(b_{1}, b_{2}, \ldots, b_{n}\right),
\end{aligned}
$$

where $b_{n}$ is grey relational grade of the tourism destination $T_{n}$ which indicates the degree of influence that the comparative sequence could exert over the referential sequence. Therefore, if a particular comparative sequence is better than the other comparative sequences to the referential sequence, then the grey relational grade for that comparative sequence and referential sequence will be higher than other grey relational grades. Finally, all tourism destinations are evaluated synthetically according to the value of $b_{n}$, where when $b_{n}$ is larger, the tourism destination $T_{n}$ is better.

\section{A Numerical Example}

In this section, we use the proposed model to evaluate 8 tourism destinations in Taiwan Province of China (including Taipei 101, National Museum, Sun Moon Lake, Alishan, Yushan National Park, Taroko National Park, Love River, and Kenting National Park). Twenty-two (22) indexes identified from literature [21] as shown in Table 1 are used in the study ("a" is the best preference out of the 8 destinations).

5.1. The Relational Grade to Ideal Destination. According to the data from Table 1, we identify the optimum column as (7.16, 7.16, 7.59, 6.40, 7.15, 8.54, 7.45, 8.04, 7.87, 6.73, 8.56, 8.60, $6.95,8.85,7.81,7.20,7.36,6.05,8.47,8.04,7.94,7.67)$, and in combination with Table 1 , an initial matrix is obtained as follows: 
TABLE 1: Overall preference measures of destinations.

\begin{tabular}{|c|c|c|c|c|c|c|c|c|}
\hline Criteria & Taipei 101 & National Museum & Sun Moon Lake & Alishan & Yushan Park & Taroko Park & Love River & Kenting Park \\
\hline Escape & 6.23 & 5.42 & $7.16^{\mathrm{a}}$ & 6.80 & 5.94 & 7.08 & 5.99 & 6.92 \\
\hline Self-actualization & $7.16^{\mathrm{a}}$ & 6.89 & 6.30 & 6.09 & 5.22 & 6.41 & 5.66 & 6.45 \\
\hline Rest/relaxation & 5.38 & 5.05 & $7.59^{\mathrm{a}}$ & 7.06 & 6.13 & 7.05 & 6.36 & 7.30 \\
\hline Medical treatment & $6.40^{\mathrm{a}}$ & 4.41 & 4.30 & 4.34 & 3.02 & 4.09 & 5.38 & 4.73 \\
\hline Health and fitness & 5.05 & 4.10 & 6.57 & 6.98 & 6.34 & $7.15^{\mathrm{a}}$ & 5.17 & 6.57 \\
\hline Visiting friend/relative & 7.96 & 5.54 & $8.54^{\mathrm{a}}$ & 7.01 & 5.88 & 6.84 & 6.86 & 7.42 \\
\hline Meeting new people & $7.45^{\mathrm{a}}$ & 5.55 & 5.98 & 5.55 & 4.37 & 5.61 & 5.76 & 6.80 \\
\hline Novelty seeking & $8.04^{\mathrm{a}}$ & 6.08 & 5.35 & 5.06 & 4.16 & 5.22 & 5.61 & 6.29 \\
\hline Culture exploration & 6.27 & $7.87^{\mathrm{a}}$ & 6.54 & 6.41 & 5.42 & 6.28 & 5.66 & 6.45 \\
\hline Adventure seeking & 3.97 & 3.43 & 5.96 & 6.56 & 6.30 & 6.67 & 4.94 & $6.73^{\mathrm{a}}$ \\
\hline Enjoying night life & $8.56^{\mathrm{a}}$ & 5.53 & 4.49 & 3.95 & 3.43 & 4.41 & 6.45 & 5.80 \\
\hline Transportation facilities & $8.60^{\mathrm{a}}$ & 8.03 & 6.20 & 5.28 & 4.04 & 5.45 & 6.78 & 6.70 \\
\hline Friendliness of people & 6.48 & 6.52 & 6.68 & 6.84 & 5.95 & 6.93 & 6.33 & $6.95^{\mathrm{a}}$ \\
\hline Quality/variety of food & $8.85^{\mathrm{a}}$ & 6.41 & 5.70 & 5.58 & 4.28 & 5.80 & 7.16 & 6.88 \\
\hline Accommodation & $7.81^{\mathrm{a}}$ & 7.26 & 6.67 & 5.72 & 4.31 & 6.63 & 7.36 & 7.52 \\
\hline Environment safety & 6.10 & 6.38 & 6.98 & 6.81 & 6.07 & $7.20^{\mathrm{a}}$ & 6.24 & 6.73 \\
\hline Personal safety & $7.36^{\mathrm{a}}$ & 7.29 & 5.80 & 5.02 & 4.55 & 5.38 & 5.80 & 6.59 \\
\hline Price & 4.39 & 5.12 & 5.55 & 5.64 & 5.88 & $6.05^{\mathrm{a}}$ & 5.30 & 5.30 \\
\hline $\begin{array}{l}\text { Culture and historical } \\
\text { resources }\end{array}$ & 6.11 & $8.47^{\mathrm{a}}$ & 6.78 & 6.72 & 6.22 & 6.63 & 5.60 & 6.49 \\
\hline Good shopping & $8.04^{\mathrm{a}}$ & 5.99 & 4.89 & 4.79 & 3.63 & 5.40 & 6.13 & 6.11 \\
\hline Destination image & 7.78 & 7.27 & $7.94^{\mathrm{a}}$ & 7.06 & 6.53 & 6.92 & 6.38 & 7.14 \\
\hline Benefits expectations & $7.67^{\mathrm{a}}$ & 6.80 & 5.41 & 5.41 & 4.60 & 5.32 & 6.48 & 6.67 \\
\hline
\end{tabular}

$$
\begin{aligned}
& R_{1} \\
& =\left[\begin{array}{lllllllllllllllllllllll}
7.16 & 7.16 & 7.59 & 6.40 & 7.15 & 8.54 & 7.45 & 8.04 & 7.87 & 6.73 & 8.56 & 8.60 & 6.95 & 8.85 & 7.81 & 7.20 & 7.36 & 6.05 & 8.47 & 8.04 & 7.94 & 7.67 \\
6.23 & 7.16 & 5.38 & 6.40 & 5.05 & 7.96 & 7.45 & 8.04 & 6.27 & 3.97 & 8.56 & 8.60 & 6.48 & 8.85 & 7.81 & 6.10 & 7.36 & 4.39 & 6.11 & 8.04 & 7.78 & 7.67 \\
5.42 & 6.89 & 5.05 & 4.41 & 4.10 & 5.54 & 5.55 & 6.08 & 7.87 & 3.43 & 5.53 & 8.03 & 6.52 & 6.41 & 7.26 & 6.38 & 7.29 & 5.12 & 8.47 & 5.99 & 7.27 & 6.80 \\
7.16 & 6.30 & 7.59 & 4.30 & 6.57 & 8.54 & 5.98 & 5.35 & 6.54 & 5.96 & 4.49 & 6.20 & 6.68 & 5.70 & 6.67 & 6.98 & 5.80 & 5.55 & 6.78 & 4.89 & 7.94 & 5.41 \\
6.80 & 6.09 & 7.06 & 4.34 & 6.98 & 7.01 & 5.55 & 5.06 & 6.41 & 6.56 & 3.95 & 5.28 & 6.84 & 5.58 & 5.72 & 6.81 & 5.02 & 5.64 & 6.72 & 4.79 & 7.06 & 5.41 \\
5.94 & 5.22 & 6.13 & 3.02 & 6.34 & 5.88 & 4.37 & 4.16 & 5.42 & 6.30 & 3.43 & 4.04 & 5.95 & 4.28 & 4.31 & 6.07 & 4.55 & 5.88 & 6.22 & 3.63 & 6.53 & 4.60 \\
7.08 & 6.41 & 7.05 & 4.09 & 7.15 & 6.84 & 5.61 & 5.22 & 6.28 & 6.67 & 4.41 & 5.45 & 6.93 & 5.80 & 6.63 & 7.20 & 5.38 & 6.05 & 6.63 & 5.40 & 6.92 & 5.32 \\
5.99 & 5.66 & 6.36 & 5.38 & 5.17 & 6.86 & 5.76 & 5.61 & 5.66 & 4.94 & 6.45 & 6.78 & 6.33 & 7.16 & 7.36 & 6.24 & 5.80 & 5.30 & 5.60 & 6.13 & 6.38 & 6.48 \\
6.92 & 6.45 & 7.30 & 4.73 & 6.57 & 7.42 & 6.80 & 6.29 & 6.45 & 6.73 & 5.80 & 6.70 & 6.95 & 6.88 & 7.52 & 6.73 & 6.59 & 5.30 & 6.49 & 6.11 & 7.14 & 6.67
\end{array}\right] .
\end{aligned}
$$

Each of the index values is normalized according to formulas (4) and (5), and then a new matrix is obtained as follows:

$X$

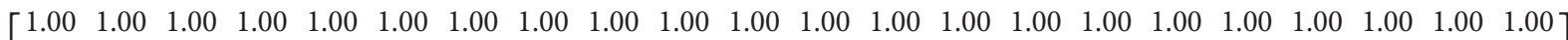

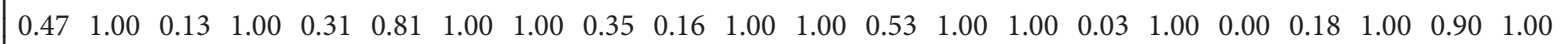

$$
\begin{aligned}
& \begin{array}{llllllllllllllllllllll}
0.00 & 0.86 & 0.00 & 0.41 & 0.00 & 0.00 & 0.38 & 0.49 & 1.00 & 0.00 & 0.41 & 0.88 & 0.57 & 0.47 & 0.84 & 0.27 & 0.98 & 0.44 & 1.00 & 0.54 & 0.57 & 0.72
\end{array} \\
& \begin{array}{llllllllllllllllllllll}
1.00 & 0.56 & 1.00 & 0.38 & 0.81 & 1.00 & 0.52 & 0.31 & 0.46 & 0.77 & 0.21 & 0.47 & 0.73 & 0.31 & 0.67 & 0.81 & 0.44 & 0.70 & 0.41 & 0.29 & 1.00 & 0.26
\end{array} \\
& =\begin{array}{lllllllllllllllllllllll}
0.79 & 0.45 & 0.79 & 0.39 & 0.94 & 0.49 & 0.38 & 0.23 & 0.40 & 0.95 & 0.10 & 0.27 & 0.89 & 0.28 & 0.40 & 0.65 & 0.17 & 0.75 & 0.39 & 0.26 & 0.44 & 0.26 & .
\end{array} \\
& \begin{array}{llllllllllllllllllllll}
0.30 & 0.00 & 0.43 & 0.00 & 0.73 & 0.11 & 0.00 & 0.00 & 0.00 & 0.87 & 0.00 & 0.00 & 0.00 & 0.00 & 0.00 & 0.00 & 0.00 & 0.90 & 0.22 & 0.00 & 0.10 & 0.00
\end{array}
\end{aligned}
$$

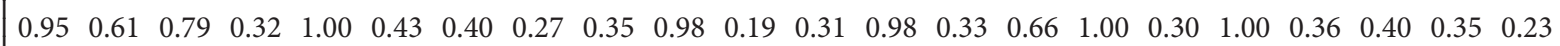

$$
\begin{aligned}
& \begin{array}{llllllllllllllllllllll}
0.33 & 0.23 & 0.52 & 0.70 & 0.35 & 0.44 & 0.45 & 0.37 & 0.10 & 0.46 & 0.59 & 0.60 & 0.38 & 0.63 & 0.87 & 0.15 & 0.44 & 0.55 & 0.00 & 0.57 & 0.00 & 0.61
\end{array} \\
& {\left[\begin{array}{llllllllllllllllllllll}
0.86 & 0.63 & 0.89 & 0.51 & 0.81 & 0.63 & 0.79 & 0.55 & 0.42 & 1.00 & 0.46 & 0.58 & 1.00 & 0.57 & 0.92 & 0.58 & 0.73 & 0.55 & 0.31 & 0.56 & 0.49 & 0.67
\end{array}\right]}
\end{aligned}
$$


According to formula (8), that is, $\xi_{i j}=(0+0.5 \times$ $1) /\left(\left|X_{0 j}-X_{i j}\right|+0.5 \times 1\right)$, we obtain the matrix of grey relational coefficients as follows:

$$
\begin{aligned}
& \xi_{i j} \\
& =\left[\begin{array}{lllllllllllllllllllllllll}
0.48 & 1.00 & 0.36 & 1.00 & 0.42 & 0.72 & 1.00 & 1.00 & 0.43 & 0.37 & 1.00 & 1.00 & 0.52 & 1.00 & 1.00 & 0.34 & 1.00 & 0.33 & 0.38 & 1.00 & 0.83 & 1.00 \\
0.33 & 0.78 & 0.33 & 0.46 & 0.33 & 0.33 & 0.45 & 0.50 & 1.00 & 0.33 & 0.46 & 0.80 & 0.54 & 0.48 & 0.76 & 0.41 & 0.95 & 0.47 & 1.00 & 0.52 & 0.54 & 0.64 \\
1.00 & 0.53 & 1.00 & 0.45 & 0.72 & 1.00 & 0.51 & 0.42 & 0.48 & 0.68 & 0.39 & 0.49 & 0.65 & 0.42 & 0.61 & 0.72 & 0.47 & 0.62 & 0.46 & 0.41 & 1.00 & 0.40 \\
0.71 & 0.48 & 0.71 & 0.45 & 0.90 & 0.50 & 0.45 & 0.39 & 0.46 & 0.91 & 0.36 & 0.41 & 0.82 & 0.41 & 0.46 & 0.59 & 0.38 & 0.67 & 0.45 & 0.40 & 0.47 & 0.40 \\
0.42 & 0.33 & 0.47 & 0.33 & 0.65 & 0.36 & 0.33 & 0.33 & 0.33 & 0.79 & 0.33 & 0.33 & 0.33 & 0.33 & 0.33 & 0.33 & 0.33 & 0.83 & 0.39 & 0.33 & 0.36 & 0.33 \\
0.92 & 0.56 & 0.70 & 0.42 & 1.00 & 0.47 & 0.46 & 0.41 & 0.44 & 0.96 & 0.38 & 0.42 & 0.96 & 0.43 & 0.60 & 1.00 & 0.42 & 1.00 & 0.44 & 0.46 & 0.43 & 0.40 \\
0.43 & 0.39 & 0.51 & 0.62 & 0.44 & 0.47 & 0.48 & 0.44 & 0.36 & 0.48 & 0.55 & 0.56 & 0.45 & 0.57 & 0.80 & 0.37 & 0.47 & 0.53 & 0.33 & 0.54 & 0.33 & 0.56 \\
0.78 & 0.58 & 0.81 & 0.50 & 0.72 & 0.57 & 0.70 & 0.53 & 0.46 & 1.00 & 0.48 & 0.55 & 1.00 & 0.54 & 0.86 & 0.55 & 0.65 & 0.53 & 0.42 & 0.53 & 0.49 & 0.61
\end{array}\right] .
\end{aligned}
$$

According to formulas (10) (13), the index weights vector is calculated as follows:

$\omega$

$$
=(0.05,0.04,0.05,0.04,0.04,0.04,0.04,0.05,0.05,0.05,0.05,0.04,0.04,0.04,0.03,0.05,0.06,0.04,0.05,0.04,0.05,0.05) \text {. }
$$

Using formula (14), we obtain the grey relational grades as follows:

$$
B=(0.73,0.57,0.61,0.53,0.40,0.60,0.48,0.63) .
$$

5.2. Comparison and Analysis. In this paper, we focus on developing a novel evaluation approach tourist choice of destination based on grey relation analysis, in order to demonstrate the advantages of the developed evaluation methods, and comparing the evaluation results with the evaluation method of “TOPSIS" used by literature [21]. So, after obtaining the grey relational grade to the ideal destination by using our proposed method, we compare and analyze these results with the evaluation results obtained from the Technique for Order Preference by Similarity to Ideal Solution (TOPSIS) used by literature [21]. The results are shown in Table 2.

As can be seen from Table 2, we can make the following comparative analysis.

(i) The ranking results obtained from literature [21] and the results in this paper are not completely the same, as shown in column 2 and column 4 of Table 2, which reflect the consistency and difference of two methods. In other words, the ranking results of the top three and the last one are the same but the others are not the same. Interestingly, almost all relational grades to ideal solution of our proposed approach are bigger than those of the similarity to ideal solution by the Technique for Order Preference by Similarity to Ideal Solution (TOPSIS) evaluation method, which shows that our proposed approach has the advantage over the TOPSIS approach.

(ii) Comparing the overall preference measures of destinations as shown in Table 1 of literature [21], it is observed that the Taroko National Park has three best preferences out of the 24 factors, and the National Palace Museum has two best preferences. Therefore, we intuitively think that the destination with more best preferences should be ranked higher than the destination with less best preferences, and the actual evaluation results are consistent with our intuition, which show that our proposed evaluation approach is more credible and more in line with the actual situation. The fundamental reason why our proposed evaluation approach is more in line with the actual situation lies in its own characteristics. In other words, the tourists' preferences to tourism destinations are grey and fuzzy, which is in line with the cognition rules of human being to the objective world.

(iii) No matter what kind of evaluation approach, Taipei 101 is ranked the number one favorite local destination. That is, Taipei 101 is worthy of visiting as it is the highest building in the world, located in the business center of Taipei city and a Taipei landmark. As shown in Table 1, Taipei 101 is considered the most desirable destination with respect to "self-actualization," "meeting new friends," "medical treatment," "novelty seeking," "enjoying night life," "transportation facilities," "quality and variety of food," "accommodation facilities," "good shopping," "personal safety," and "benefit expectations," which reflects the consistency of two methods.

\section{Conclusions}

From a methodological point of view, we proposed a grey relation analysis evaluation model for choosing tourism destinations and the findings demonstrate that the grey relation analysis evaluation approach is a useful tool to help support a decision in destination choice. It integrates the opinion 
TABLE 2: Final ranking of destinations.

\begin{tabular}{lcccc}
\hline & $\begin{array}{c}\text { Results of literature } \\
{[21]}\end{array}$ & \multicolumn{2}{c}{ Results in this paper } \\
Destination & Rank & $\begin{array}{c}\text { Similarity to } \\
\text { ideal } \\
\text { solution }\end{array}$ & Rank & $\begin{array}{c}\text { Relational } \\
\text { grade to ideal } \\
\text { solution }\end{array}$ \\
\hline $\begin{array}{l}\text { Taipei 101 } \\
\text { Kenting }\end{array}$ & 1 & 0.75 & 1 & 0.73 \\
$\begin{array}{l}\text { National Park } \\
\text { Sun Moon Lake }\end{array}$ & 2 & 0.63 & 2 & 0.63 \\
$\begin{array}{l}\text { National Palace } \\
\text { Museum }\end{array}$ & 4 & 0.55 & 3 & 0.61 \\
$\begin{array}{l}\text { Love River } \\
\text { Taroko }\end{array}$ & 5 & 0.48 & 5 & 0.57 \\
$\begin{array}{l}\text { National Park } \\
\text { Alishan }\end{array}$ & 6 & 0.43 & 4 & 0.60 \\
$\begin{array}{l}\text { Yushan } \\
\text { National Park }\end{array}$ & 8 & 0.37 & 6 & 0.53 \\
\hline
\end{tabular}

and evaluation of experts and makes the complex decisionmaking system into a simple grey relation analysis system. In other words, our proposed evaluation approach makes the evaluation process simple and easy to conduct. What is more, it is especially preferred in ordering the alternatives in situations in which the sample is small and sample distribution is not known. In our future studies, we will apply the approach to evaluating other tourism destinations in China and make a ranking for Chinese main tourism destinations.

\section{Competing Interests}

The authors declare that there are no competing interests regarding the publication of this paper.

\section{Acknowledgments}

This study is supported by the National Natural Science Foundation of China under Grant no. 41440045.

\section{References}

[1] V. S. Lin, R. Mao, and H. Song, “Tourism expenditure patterns in China," Annals of Tourism Research, vol. 54, pp. 100-117, 2015.

[2] Domestic Tourism, National Bureau of Statistics of China, 2014, http://data.stats.gov.cn/english/easyquery.htm? $\mathrm{cn}=\mathrm{C} 01$.

[3] S. C. S. Jang and S. Ham, "A double-hurdle analysis of travel expenditure: baby boomer seniors versus older seniors," Tourism Management, vol. 30, no. 3, pp. 372-380, 2009.

[4] T. Huybers and J. Bennett, "Impact of the environment on holiday destination choices of prospective UK tourists: implications for Tropical North Queensland," Tourism Economics, vol. 6, no. 1, pp. 21-46, 2000.

[5] H. R. Seddighi and A. L. Theocharous, "A model of tourism destination choice: a theoretical and empirical analysis," Tourism Management, vol. 23, no. 5, pp. 475-487, 2002.

[6] G. Lee, J. T. O’Leary, L. Sunhee, and A. Morrison, "Comparison and contrast of push and pull motivational effects on trip behavior: an application of a multinomial logistic regression model," Tourism Analysis, vol. 7, no. 2, pp. 89-104, 2001.

[7] H. Oppewal, T. Huybers, and G. I. Crouch, "Tourist destination and experience choice: a choice experimental analysis of decision sequence effects," Tourism Management, vol. 48, pp. 467476, 2015.

[8] A. Molina and Á. Esteban, "Tourism brochures: usefulness and image," Annals of Tourism Research, vol. 33, no. 4, pp. 1036-1056, 2006.

[9] H. Kim, C.-K. Cheng, and J. T. O'Leary, "Understanding participation patterns and trends in tourism cultural attractions," Tourism Management, vol. 28, no. 5, pp. 1366-1371, 2007.

[10] L. Jin, Y. He, and H. Song, "Service customization: to upgrade or to downgrade? An investigation of how option framing affects tourists' choice of package-tour services," Tourism Management, vol. 33, no. 2, pp. 266-275, 2012.

[11] J. Ashwell, "Going bush? Factors which influence international tourists' decisions to travel to remote Australian destinations," Tourism Management, vol. 46, pp. 80-83, 2015.

[12] V. V. Can, "Estimation of travel mode choice for domestic tourists to Nha Trang using the multinomial probit model," Transportation Research Part A: Policy and Practice, vol. 49, pp. 149-159, 2013.

[13] L. Wu, J. Zhang, and A. Fujiwara, “Tourism participation and expenditure behaviour: analysis using a scobit based discretecontinuous choice model," Annals of Tourism Research, vol. 40, no. 1, pp. 1-17, 2013.

[14] G. Prayag and C. Ryan, "Antecedents of tourists' loyalty to mauritius: the role and influence of destination image, place attachment, personal involvement, and satisfaction," Journal of Travel Research, vol. 51, no. 3, pp. 342-356, 2012.

[15] N. K. Prebensen, E. Woo, J. S. Chen, and M. Uysal, "Motivation and involvement as antecedents of the perceived value of the destination experience," Journal of Travel Research, vol. 52, no. 2, pp. 253-264, 2013.

[16] H. Song, R. van der Veen, G. Li, and J. L. Chen, “The Hong Kong tourist satisfaction index," Annals of Tourism Research, vol. 39, no. 1, pp. 459-479, 2012.

[17] J.-Y. Wong and C. Yeh, "Tourist hesitation in destination decision making," Annals of Tourism Research, vol. 36, no. 1, pp. 6-23, 2009.

[18] B. M. Josiam, D. L. Spears, S. Pookulangara, K. Dutta, T. R. Kinley, and J. L. Duncan, "Using structural equation modeling to understand the impact of Bollywood movies on destination image, tourist activity, and purchasing behavior of Indians," Journal of Vacation Marketing, vol. 21, no. 3, pp. 251-261, 2015.

[19] R. Pinky Pawaskar and M. Goel, "Improving the efficacy of destination marketing strategies: a structural equation model for leisure travel," Indian Journal of Science and Technology, vol. 9, no. 15, pp. 1-11, 2016.

[20] H. Zhang, X. Fu, L. A. Cai, and L. Lu, "Destination image and tourist loyalty: a meta-analysis," Tourism Management, vol. 40, pp. 213-223, 2014.

[21] T.-K. Hsu, Y.-F. Tsai, and H.-H. Wu, “The preference analysis for tourist choice of destination: a case study of Taiwan," Tourism Management, vol. 30, no. 2, pp. 288-297, 2009.

[22] J.-H. Huang and K.-H. Peng, "Fuzzy Rasch model in TOPSIS: a new approach for generating fuzzy numbers to assess the competitiveness of the tourism industries in Asian countries," Tourism Management, vol. 33, no. 2, pp. 456-465, 2012. 
[23] M. H. N. Salleh, R. Othman, and T. Sarmidi, "Tourist satisfaction of the environmental service quality for Tioman Island Marine Park," Indian Journal of Geo-Marine Sciences, vol. 41, no. 2, pp. 173-179, 2012.

[24] D. Mohamad and R. M. Jamil, "A Preference analysis model for selecting tourist destinations based on motivational factors: a Case Study in Kedah, Malaysia," Procedia-Social and Behavioral Sciences, vol. 65, pp. 20-25, 2012.

[25] M. Cucculelli and G. Goffi, "Does sustainability enhance tourism destination competitiveness? Evidence from Italian destinations of excellence," Journal of Cleaner Production, vol. 111, pp. 370-382, 2016.

[26] J. K. S. Jacobsen and A. M. Munar, “Tourist information search and destination choice in a digital age," Tourism Management Perspectives, vol. 1, no. 1, pp. 39-47, 2012.

[27] A. H. N. Mak, M. Lumbers, A. Eves, and R. C. Y. Chang, "An application of the repertory grid method and generalised Procrustes analysis to investigate the motivational factors of tourist food consumption," International Journal of Hospitality Management, vol. 35, pp. 327-338, 2013.

[28] G. Fuchs, N. Uriely, A. Reichel, and D. Maoz, "Vacationing in a terror-stricken destination: tourists' risk perceptions and rationalizations," Journal of Travel Research, vol. 52, no. 2, pp. 182-191, 2013

[29] W. Elias and Y. Shiftan, "The influence of individual's risk perception and attitudes on travel behavior," Transportation Research Part A: Policy and Practice, vol. 46, no. 8, pp. 1241-1251, 2012.

[30] S. Pike and S. J. Page, "Destination marketing organizations and destination marketing: anarrative analysis of the literature," Tourism Management, vol. 41, pp. 202-227, 2014.

[31] G. I. Crouch and J. R. B. Ritchie, "Application of the analytic hierarchy process to tourism choice and decision making: a review and illustration applied to destination competitiveness," Tourism Analysis, vol. 10, no. 1, pp. 17-25, 2005.

[32] D. Das and K. Mukherjee, "Development of an AHP-QFD framework for designing a tourism product," International Journal of Services and Operations Management, vol. 4, no. 3, pp. 321-344, 2008.

[33] H. N. Ali, A. A. I. Sabri, and M. M. N. Noor, "Rating and ranking criteria for selected Islands using fuzzy analytic hierarchy process (FAHP)," International Journal of Applied Mathematics and Informatics, vol. 1, no. 6, pp. 57-65, 2012.

[34] G. Fan, E. D. Goodman, and Z. Liu, "AHP (analytic hierarchy process) and computer analysis software used in tourism safety," Journal of Software, vol. 8, no. 12, pp. 3114-3119, 2013.

[35] K. J. Pool, M. Amani, and A. Haroni, "Assessment of alternatives for tourism destinations advertising using AIDA model and AHP approach," Asian Journal of Research in Marketing, vol. 3, no. 3, pp. 88-97, 2014.

[36] Y. Zhou, K. Maumbe, J. Deng, and S. W. Selin, "Resource-based destination competitiveness evaluation using a hybrid analytic hierarchy process (AHP): the case study of West Virginia," Tourism Management Perspectives, vol. 15, pp. 72-80, 2015.

[37] X. Wang, X. R. Li, F. Zhen, and J. Zhang, "How smart is your tourist attraction?: measuring tourist preferences of smart tourism attractions via a FCEM-AHP and IPA approach," Tourism Management, vol. 54, pp. 309-320, 2016.

[38] J. S. Chen and D. Gursoy, "An investigation of tourists' destination loyalty and preferences," International Journal of Contemporary Hospitality Management, vol. 13, no. 2, pp. 79-85, 2001.
[39] M. Kozak, "Comparative analysis of tourist motivations by nationality and destinations," Tourism Management, vol. 23, no. 3, pp. 221-232, 2002.

[40] J. De Vos, P. L. Mokhtarian, T. Schwanen, V. Van Acker, and F. Witlox, "Travel mode choice and travel satisfaction: bridging the gap between decision utility and experienced utility," Transportation, vol. 43, no. 5, pp. 771-796, 2016.

[41] U. Pröbstl-Haider, W. Haider, V. Wirth, and B. Beardmore, "Will climate change increase the attractiveness of summer destinations in the European Alps? A survey of German tourists," Journal of Outdoor Recreation and Tourism, vol. 11, pp. 44-57, 2015.

[42] A. Garg, "Travel risks vs tourist decision making: a tourist perspective," International Journal of Hospitality \& Tourism Systems, vol. 8, no. 1, pp. 1-9, 2015.

[43] S. Amaro and P. Duarte, "An integrative model of consumers' intentions to purchase travel online," Tourism Management, vol. 46, pp. 64-79, 2015.

[44] Z. Tang, "An integrated approach to evaluating the coupling coordination between tourism and the environment," Tourism Management, vol. 46, pp. 11-19, 2015.

[45] N. Paker and C. A. Vural, "Customer segmentation for marinas: evaluating marinas as destinations," Tourism Management, vol. 56, pp. 156-171, 2016.

[46] T. Huybers, "Modelling short-break holiday destination choices," Tourism Economics, vol. 9, no. 4, pp. 389-405, 2003.

[47] B. G. C. Dellaert, D. F. Ettema, and C. Lindh, "Multi-faceted tourist travel decisions: a constraint-based conceptual framework to describe tourists' sequential choices of travel components," Tourism Management, vol. 19, no. 4, pp. 313-320, 1998.

[48] E. Sirakaya and A. G. Woodside, "Building and testing theories of decision making by travellers," Tourism Management, vol. 26, no. 6, pp. 815-832, 2005.

[49] T. Lam and C. H. C. Hsu, "Predicting behavioral intention of choosing a travel destination," Tourism Management, vol. 27, no. 4, pp. 589-599, 2006.

[50] C. Goossens, "Tourism information and pleasure motivation," Annals of Tourism Research, vol. 27, no. 2, pp. 301-321, 2000.

[51] V. C. S. Heung, H. Qu, and R. Chu, "The relationship between vacation factors and socio-demographic and travelling characteristics: the case of Japanese leisure travellers," Tourism Management, vol. 22, no. 3, pp. 259-269, 2001.

[52] S. S. Kim and B. Prideaux, "Marketing implications arising from a comparative study of international pleasure tourist motivations and other travel-related characteristics of visitors to Korea," Tourism Management, vol. 26, no. 3, pp. 347-357, 2005.

[53] M. Kozak, "Comparative analysis of tourist motivations by nationality and destinations," Tourism Management, vol. 23, no. 3, pp. 221-232, 2002.

[54] G. Richards and J. Wilson, “Today's youth travellers: Tomorrow's global nomads. New horizons in independent youth and student travel," International Student Travel Confederation (ISTC), 2003.

[55] N. Tomiš, B. Kovaţeviš, N. Berber, and N. Milišs, "Factors influencing the motivation of young people when choosing a city destination in Europe-a case study from Esbjerg (Denmark)," European Researcher, vol. 69, no. 2, pp. 414-428, 2014.

[56] X. D. Guo, H. L. Zhang, and J. H. Ruan, "A novel similaritybased algorithm for classifying tourism scenic spots," ICIC Express Letters, Part B: Applications, vol. 6, no. 2, pp. 503-509, 2015. 
[57] J. Morán, E. Granada, J. L. Míguez, and J. Porteiro, "Use of grey relational analysis to assess and optimize small biomass boilers," Fuel Processing Technology, vol. 87, no. 2, pp. 123-127, 2006.

[58] D. Ju-Long, "Control problems of grey systems," Systems \& Control Letters, vol. 1, no. 5, pp. 288-294, 1982.

[59] R.-T. Wang, C.-T. B. Ho, and K. Oh, "Measuring production and marketing efficiency using grey relation analysis and data envelopment analysis," International Journal of Production Research, vol. 48, no. 1, pp. 183-199, 2010.

[60] C.-T. Ho, "Measuring bank operations performance: an approach based on Grey Relation Analysis," Journal of the Operational Research Society, vol. 57, no. 4, pp. 337-349, 2006.

[61] C.-Y. Kung and K.-L. Wen, "Applying Grey Relational Analysis and Grey Decision-Making to evaluate the relationship between company attributes and its financial performance-a case study of venture capital enterprises in Taiwan," Decision Support Systems, vol. 43, no. 3, pp. 842-852, 2007.

[62] Y.-J. Wang, "Combining grey relation analysis with FMCGDM to evaluate financial performance of Taiwan container lines," Expert Systems with Applications, vol. 36, no. 2, pp. 2424-2432, 2009.

[63] P. T.-W. Lee, C.-W. Lin, and S.-H. Shin, "A comparative study on financial positions of shipping companies in Taiwan and Korea using entropy and grey relation analysis," Expert Systems with Applications, vol. 39, no. 5, pp. 5649-5657, 2012.

[64] F. Ecer and A. Boyukaslan, "Measuring performances of football clubs using financial ratios: the gray relational analysis approach," American Journal of Economics, vol. 4, no. 1, pp. 6271, 2014

[65] S. J. Lin, I. J. Lu, and C. Lewis, "Grey relation performance correlations among economics, energy use and carbon dioxide emission in Taiwan," Energy Policy, vol. 35, no. 3, pp. 1948-1955, 2007.

[66] I. J. Lu, S. J. Lin, and C. Lewis, "Grey relation analysis of motor vehicular energy consumption in Taiwan," Energy Policy, vol. 36, no. 7, pp. 2556-2561, 2008.

[67] S. H. Hashemi, A. Karimi, and M. Tavana, "An integrated green supplier selection approach with analytic network process and improved Grey relational analysis," International Journal of Production Economics, vol. 159, pp. 178-191, 2015.

[68] D. G. Pearce, “Tourist time-budget," Annals of Tourism Research, vol. 15, no. 1, pp. 106-121, 1988.

[69] D. Ju-Long, "Introduction to grey system theory," The Journal of Grey System, vol. 1, no. 1, pp. 1-24, 1989.

[70] U. Çaydaş and A. Hasçalık, "Use of the grey relational analysis to determine optimum laser cutting parameters with multiperformance characteristics," Optics \& Laser Technology, vol. 40, no. 7, pp. 987-994, 2008. 

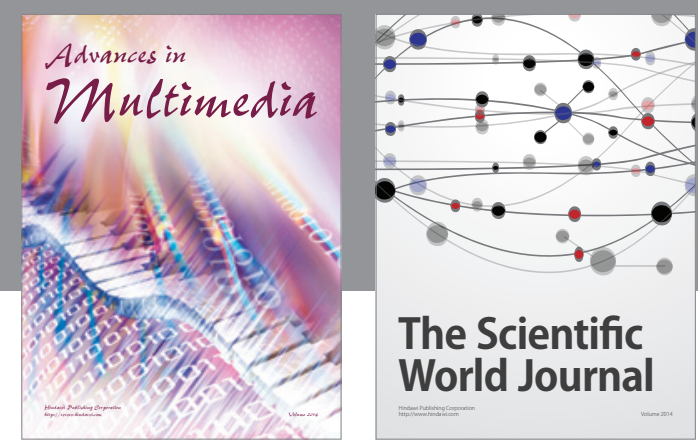

The Scientific World Journal
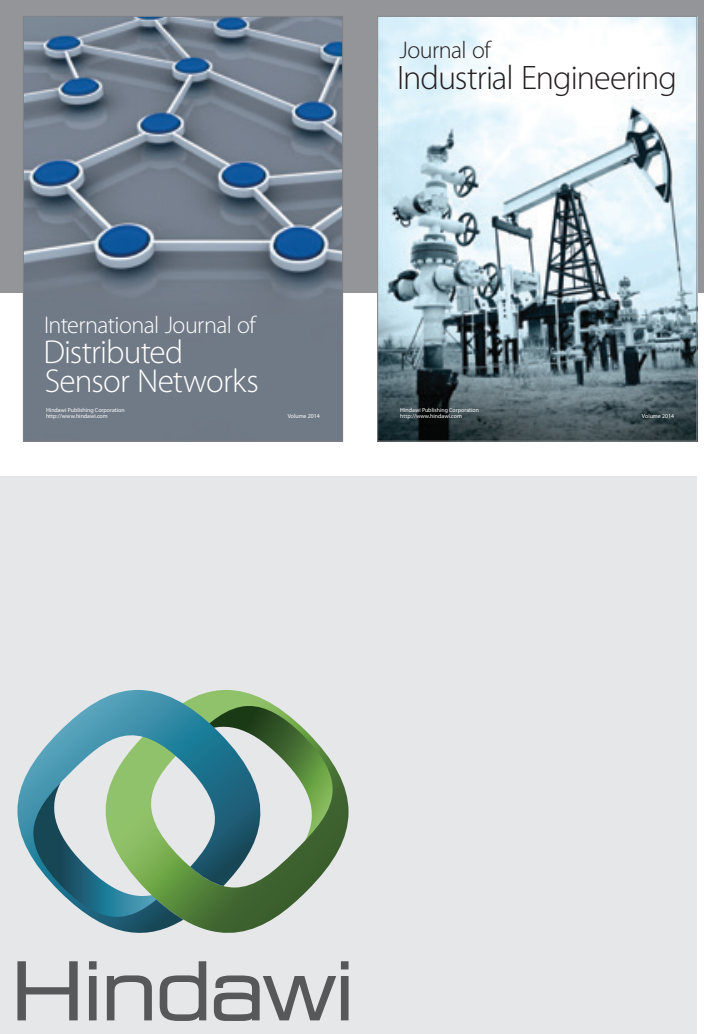

Submit your manuscripts at

http://www.hindawi.com

\section{Computer Networks} and Communications
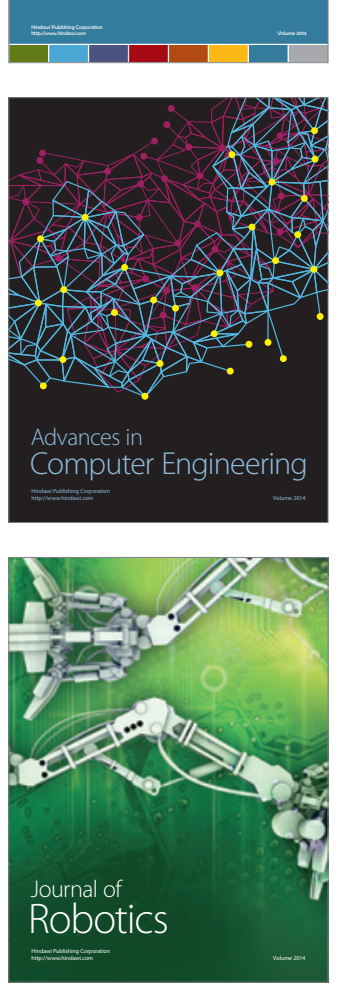
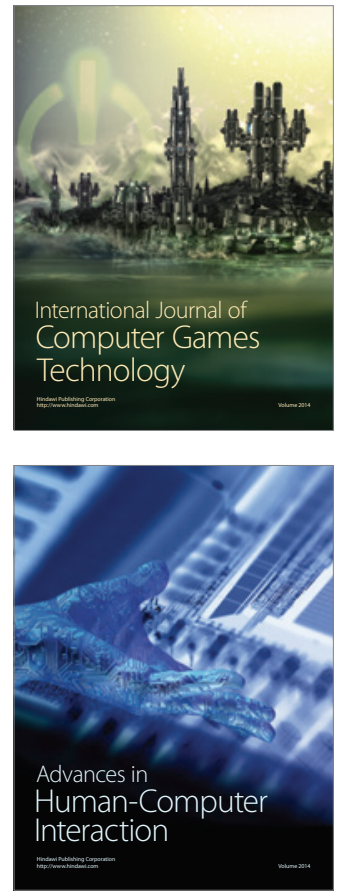
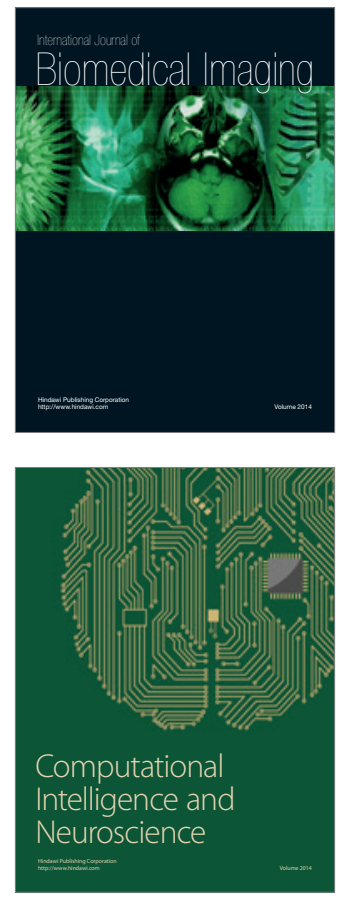
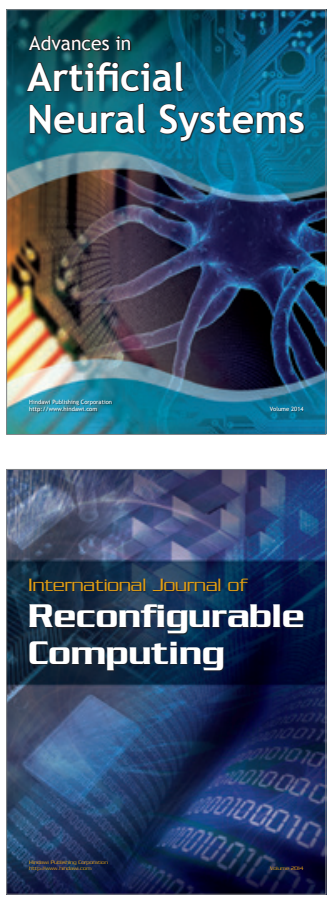
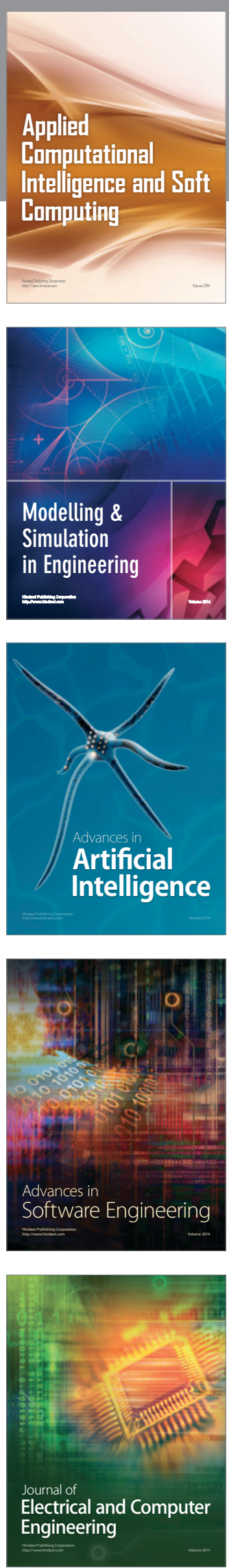